\title{
First law thermodynamic analysis of the recuperated Humphrey cycle for gas turbines with pressure gain combustion
}

\author{
Panagiotis Stathopoulos, Tim Rähse, Johann Vinkeloe, Neda Djordjevic \\ TU Berlin, Institute of Fluids Dynamics and Technical Acoustics \\ Müller-Breslau Strasse 8, 10623, Berlin, Germany
}

\begin{abstract}
The current work is an analysis of the recuperated Humphrey cycle. Three cycle topologies are studied with and without turbine cooling. The study focuses on the interconnection between combustor pressure gain and heat recuperation. It is an attempt to optimize the cycle topology and configuration to achieve the maximum possible cycle efficiency. It is found that the best option to use recuperation in the Humphrey cycle is to operate the combustor at stoichiometric conditions, without preheating the air fed to it. The combustion air comes effectively form a compressor air bleed. The remaining air is further compressed at the combustor outlet pressure and is fed to a plenum between combustor and turbine once it is preheated by the recuperator. This cycle configuration results in the best performance both in terms of efficiency and specific work. Specifically, an efficiency increase between 2 to 5 percentage points is achieved. This work concludes with a feasibility study for shockless explosion combustion (SEC) for the Humphrey cycle configurations and topologies that achieve an efficiency advantage against the Joule cycle. It is found that realistic SEC combustor lengths and efficiency gains can be simultaneously achieved, albeit not at the cycle configurations with the best performance.
\end{abstract}

Keywords: Pressure gain combustion, Humphrey cycle, Recuperation, Gas

\footnotetext{
*Panagiotis Stathopoulos

Email address: stathopoulos@tu-belrin.de (Neda Djordjevic)
} 
turbine, Emissions, Thermodynamic analysis

\section{Introduction}

Variable renewable generation has already increased the demand for network services across Europe [1. Among other options, gas turbines are a technology able to deliver these services [2. At the same time, gas turbines offer great potential as back conversion components in hydrogen large scale electric energy storage systems. Apart form their potential in the power sector, gas turbines are currently the only technology that can be effectively applied in the aviation sector. These characteristics have led in a large amount of $R \& D$ in the past decades, thus making them a very mature technology. As a result, any increase in their thermal efficiency comes at a very high additional research and development cost. In an effort to solve this issue, Pressure Gain Combustion (PGC) has emerged as a very promising concept [3, 4, 5]. Pressure gain combustion can be realized either through an approximation of constant volume combustion or through detonative combustion. The latter refers primarily to pulsed (PDC) [6] and rotating detonation combustion (RDC) [7, 8, 9]. For the former, pulsed resonant combustion [10] is the oldest approach, while shockless explosion combustion [11, 12, 13, 14, and constant volume combustion are generally applied [15].

Typically gas turbine processes with approximations of constant volume combustion are modeled with the Humphrey cycle, while the ZND cycle and its variations are used for cycles with detonative pressure gain combustion. The first thorough analysis of both cycles has been presented by Heiser and Pratt [3. They indicated that the reason behind their higher thermal efficiency in comparison to the Joule cycle is the more efficient heat addition process. However, gas dynamic phenomena in pressure gain combustors result in lower mass-averaged outlet conditions than in the model of Heiser and Pratt. As a result, their model overestimated the cycle thermal efficiency [16]. This effect can be partially accounted for a thermodynamically equivalent steady state at 
the combustor outlet, which can be subsequently applied in steady state cycle computations. Examples of this approach can be found in the works of Endo and Fujiwara [17, Nordeen [4] and Nalim [18] for pulsed, rotating detonation combustion and constant volume combustion, respectively. If insights in the phenomena in the combustor are necessary, the Euler equations with source terms for the chemical reactions [14, 19, 11] can be solved. From the resulting data, mass averaged values of the total temperature and pressure can be computed and used in a simplified thermodynamic cycle [12, 16]. Although this approach delivers more information on the origin of combustor losses and operation, it makes the analysis of alternative cycle configurations very time consuming.

Up to date, studies of gas turbines with pressure gain combustion have considered the simple open cycle configuration. The current work aims to explore alternative cycle configurations and it builds upon the results and considerations presented in a previous work of the authors on the steam injected Humphrey cycle 20. Here, the recuperated Humphrey cycle is studied in more detail than in the past [5, 21, with the aim to explore cycle designs and their effect in the operation of the combustor and the cycle thermal efficiency.

In summary, answers to the following questions on the recuperated Humphrey gas turbine cycle are sought:

- How does the efficiency of the recuperated Humphrey cycle compare with that of the respective Joule cycle?

- What different cycle designs are possible and what is their impact on cycle efficiency?

- What is the effect of heat recuperation and the different cycle topologies on the feasibility of the shockless explosion combustion (SEC) process [14]?

The present work builds on the Humphrey cycle model presented in previous works of the authors [20, 22]. A new steady model of the recuperated Humphrey cycle has been developed in Aspen plus, the details of which are presented in 
section 2. The work concludes with the results on the various cycle topologies and a recommendation on the studied cycle in the context of current research in pressure gain combustion.

\section{Methods and modeling approach}

\subsection{Recuperated gas turbine model}

Heat recuperation is one of the easiest ways to increase the thermal efficiency of a gas turbine. Heat from the turbine exhaust is transferred to the combustion air with the help of a recuperator. This way, the amount of fuel that has to be burnt to reach a specific turbine inlet temperature is reduced. Figure 1 presents a schematic of the recuperated Joule cycle. Recuperation is possible if the compressor outlet temperature is lower than that at the turbine outlet $\left(T_{4}>T_{2}\right.$ in Fig. 11). Figure 2 presents the efficiency of the ideal recuperated Joule cycle along with the aforementioned temperature difference for three values of the turbine inlet temperature. The ideal recuperated cycle can be realized for a limited number of cycle pressure ratios and the effect of recuperation on the thermal efficiency is reduced with increasing pressure ratio.

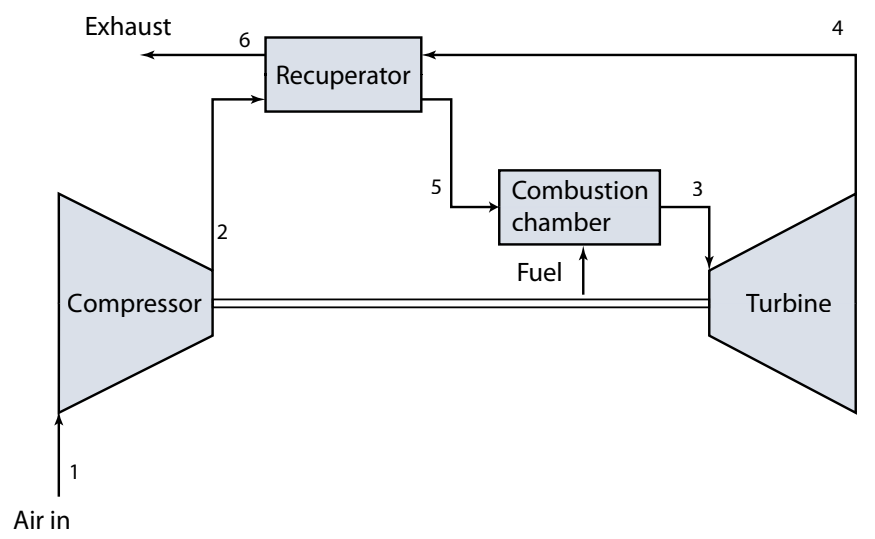

Figure 1: Schematic of the recuperated Joule cycle

For these reasons and because of the recuperator's cost, the recuperated cycle has been so far primarily applied in micro gas turbines. In these cases, 


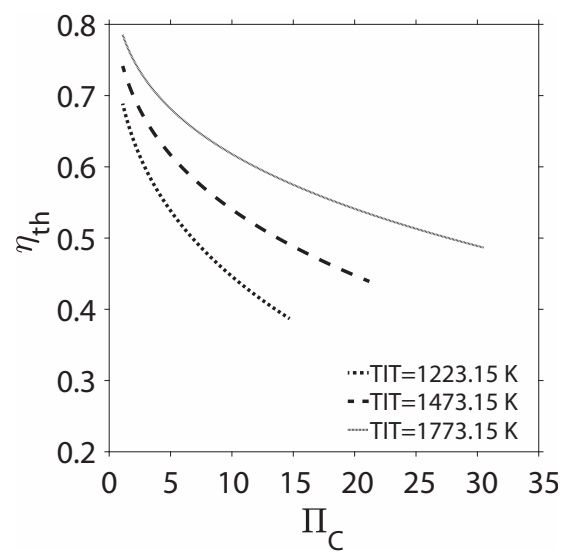

(a) Thermal efficiency of the ideal recuperated Joule cycle

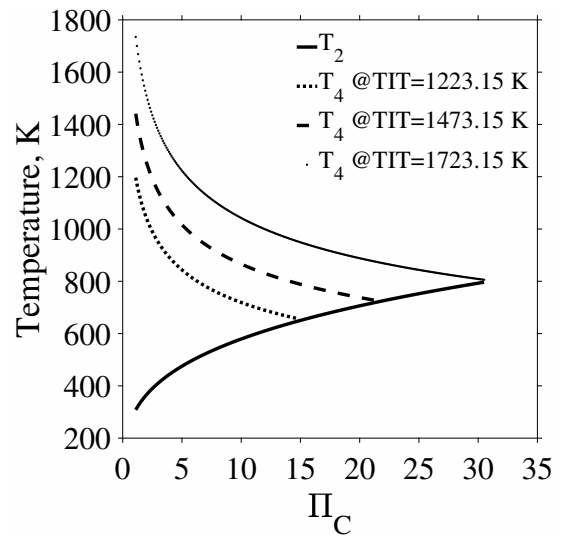

(b) Compressor $\left(T_{2}\right)$ and turbine $\left(T_{4}\right)$ outlet temperatures

Figure 2: Thermal efficiency, compressor $\left(T_{2}\right)$ and turbine $\left(T_{4}\right)$ outlet temperatures of the ideal recuperated Joule cycle

pressure ratios are limited to approximately 5 and no turbine cooling is applied, thus limiting the turbine inlet temperature to values below $1273 \mathrm{~K}$. Another practical constraint is the hot stream temperature at the recuperator inlet. Typically, cost-effective heat exchangers operate at temperatures below 923.75 K. This means that recuperated gas turbines with higher turbine inlet temperatures must necessarily have higher pressure ratios to limit the turbine outlet temperature below this value.

Despite these constraints, the current work intends to study the cycle for a broad variety of pressure ratios and turbine inlet temperatures. In order to do this, Aspen plus is used and the studied cycle topologies are divided in two categories; one with and one without turbine cooling. The reference cycle topologies for each category are shown in Fig. 3 for the recuperated Joule cycle.

The category 1 models consist of a compressor, a combustor, an uncooled turbine and a recuperator. Typically, uncooled turbines in a recuperated cycle are one-stage radial turbines with relatively low isentropic efficiency. As a result, 


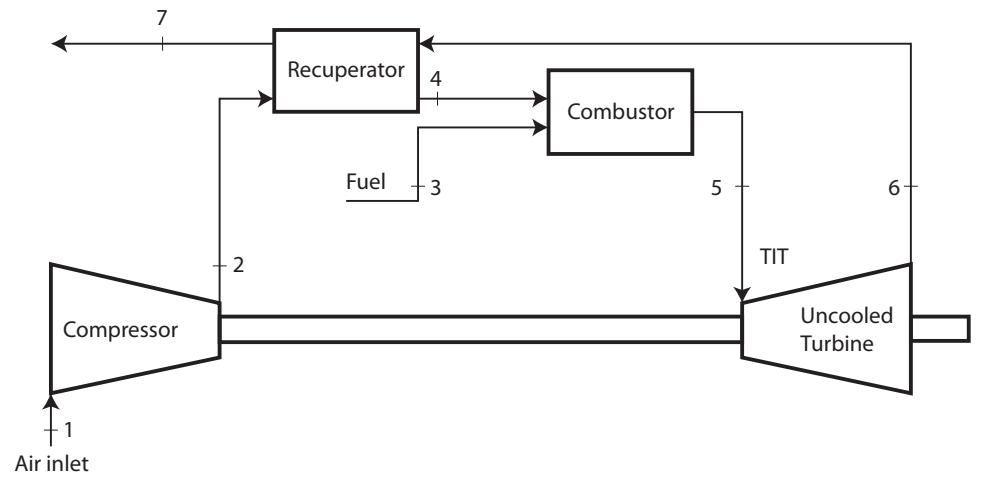

(a) Reference cycle topology for the uncooled (category 1) Joule cycle

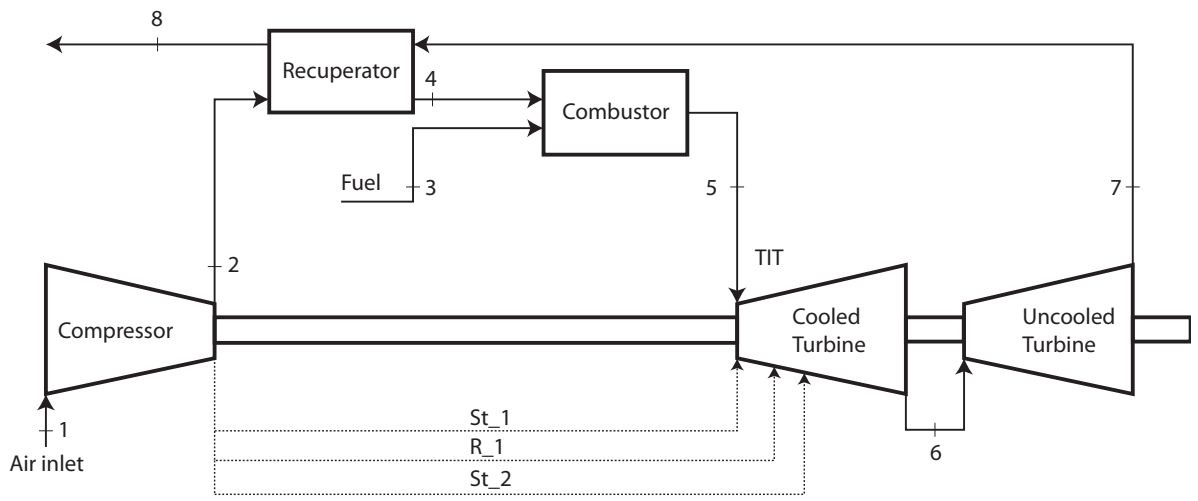

(b) Reference cycle topology for the cooled (category 2) Joule cycle

Figure 3: Cycle categories

each of the two model categories have different values for the turbomachinery isentropic efficiencies, which are presented along with several model parameters in Tab. 1. The values for the compressor and turbine isentropic efficiency of the models in category 1 are taken from the experience of the authors in modeling micro gas turbines [23, 24].

The category 2 models include a full parametric model for the cooling of a three stage turbine, the total expansion ratio of which is equally distributed among its stages. The applied secondary air system model is the same as in 22 , 25. The cooling air flow rates are computed with the assumption of a constant 
external Stanton number $S t_{g}[26,27$. The model splits the expansion in a turbine stage in a mixing step at the outlet of the stator row an expansion in the rotor row and a last mixing step of the exhaust gas with the cooling air at the rotor outlet. Pressure drop during each mixing process is taken into account by a loss coefficient shown in Tab 2 , along with all other cooling model parameters. As a result of the model assumptions, only the first three turbine blade rows need cooling air. In the Humphrey cycle model, the cooling air for the first stator row must be compressed to the combustor outlet pressure, due to the pressure gain across the latter.

\begin{tabular}{|c|c|c|c|c|c|}
\hline & \multirow[b]{2}{*}{ Symbol } & \multicolumn{2}{|c|}{ Category 1} & \multicolumn{2}{|c|}{ Category 1} \\
\hline & & Joule & Humphrey & Joule & Humphrey \\
\hline Compressor & $\eta_{i s C}$ & \multicolumn{2}{|r|}{0.82} & \multicolumn{2}{|r|}{0.9} \\
\hline Cooling air compr. & $\eta_{i s C-c o o l}$ & \multicolumn{2}{|r|}{0.82} & \multicolumn{2}{|r|}{0.9} \\
\hline Mixing element & $\delta p_{\text {mixer }}$ & $0.05 p_{\text {in }}$ & $0.15 p_{\text {in }}$ & $0.05 p_{\text {in }}$ & $0.15 p_{i n}$ \\
\hline \multirow[t]{3}{*}{ Turbine } & $\eta_{i s T}$ & \multicolumn{2}{|r|}{0.85} & \multicolumn{2}{|r|}{0.9} \\
\hline & $\delta p_{\text {stage }}$ & \multicolumn{2}{|r|}{$\mathrm{N} / \mathrm{A}$} & \multicolumn{2}{|c|}{$p_{3}{ }^{-\frac{1}{3}}$} \\
\hline & TOT & \multicolumn{4}{|c|}{$873.15 \mathrm{~K}, 923.15 \mathrm{~K}, 973.15 \mathrm{~K}$} \\
\hline \multirow[t]{4}{*}{ Recuperator } & $\epsilon$ & \multicolumn{4}{|c|}{0.9} \\
\hline & $\delta p_{r c}$ & \multicolumn{4}{|c|}{0} \\
\hline & $\delta p_{r h}$ & \multicolumn{4}{|c|}{0} \\
\hline & Pinch value & \multicolumn{4}{|c|}{$5 \mathrm{~K}$} \\
\hline
\end{tabular}

Table 1: Model parameters and assumptions

The model of the recuperated Humphrey cycle comprises again a compressor, followed by a mixing element for fuel and air that models inlet pressure loss at the PGC. The combustor model is the same user defined function as in previous publications of the authors 20, 22], and is an adaptation of the model presented by Nalim [18. Pressure gain combustion is represented by a constant volume combustion process. The flow work consumed during the expulsion of the gas from a pressure gain combustor is modeled through an isentropic expansion. The 


\begin{tabular}{lll}
\hline Parameter & Symbol & Value \\
\hline Cooling efficiency & $\eta_{\text {Cooling }}$ & 0.9 \\
Film cooling effectiveness & $\varepsilon_{F}$ & 0.4 \\
Level of technology constant & $\mathrm{C}$ & 0.045 \\
Pressure loss constant & $\mathrm{K}$ & 0.07 \\
Blade material temperature & $T_{b l}$ & $1100 \mathrm{~K}$ \\
Pressure loss due to mixing & $\delta p_{m i x}$ & $1 \%$ \\
\hline
\end{tabular}

Table 2: Cooling system model parameters based on the model from [27] for the cycle category 2

model delivers this way an equivalent, steady combustor outlet thermodynamic state that is used in the Humphrey cycle computations.

Figure 4 shows the thermodynamic states of the working medium in the combustor model. Three thermodynamic states describe the combustion process, the combustor inlet (A), that at the end of the constant volume heat addition (B) and the one after then end of the isentropic expansion process (3).

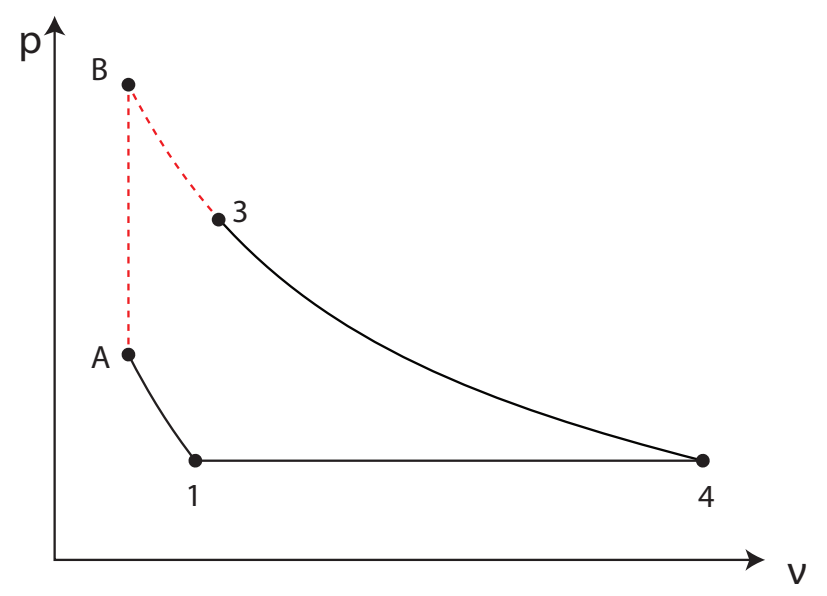

Figure 4: Pressure-specific volume diagram of the ideal Humphrey cycle. The dashed line corresponds to the combustor model.

The pressure and temperature at $\mathrm{B}$ can be computed with eq. 1 with the assumption of constant material properties (computed at the average conditions 
in the chamber). The energy conservation equation in the combustor is then used to calculate $\mathrm{T}_{3}$ from eq. 1 .

$$
Q=\dot{m} \cdot c_{v} \cdot\left(T_{B}-T_{A}\right)=\dot{m} \cdot c_{p} \cdot\left(T_{3}-T_{A}\right)
$$

In eq1. $\mathrm{Q}$ is the total heat input in the combustor, based on the lower heating value of the fuel, and $\dot{m}$ is the mass flow rate entering it. Dimethyl ether is used as fuel in both cycle models, due to its ignition properties and its relatively good fit for shockless explosion combustion [13, 28. The pressure at B results from eq2, with the assumption of a calorically perfect working medium.

$$
\frac{T_{B}}{T_{A}}=\frac{p_{B}}{p_{A}}
$$

An isentropic expansion process that starts from point B and has a temperature ratio $\frac{T_{B}}{T_{3}}$ delivers the final combustor outlet outlet pressure (eq. 3 .

$$
\frac{p_{3}}{p_{B}}=\left(\frac{T_{3}}{T_{B}}\right)^{\frac{\gamma}{\gamma-1}}
$$

Equations 133 calculate the equivalent outlet state of the combustor, based on its inlet conditions. In the current work, combustion non-idealities that result in lower combustor pressures are not accounted for, to simplify the presentation of the results. The reader is directed to past contributions of the authors 20,22 , where the impact of these phenomena on the combustor operation and cycle efficiency has been studied in detail.

\subsection{Shockless explosion combustion and combustor length calculation}

Shockless explosion combustion (SEC) is a pressure gain combustion concept that uses simultaneous auto-ignition in a combustible mixture. Chemical and acoustic time scales in the combustor are exploited to realize the four distinct phases of this cyclic process, which are presented in a time-space diagram in Fig. 5. Phase 1 starts with the homogeneous auto-ignition of the mixture, followed by a heat release and a pressure rise in the combustor. Phase 1 includes the time that the pressure wave takes to travel to the open combustor end. Phase 2 starts when this wave is reflected at the open end as a suction wave. 


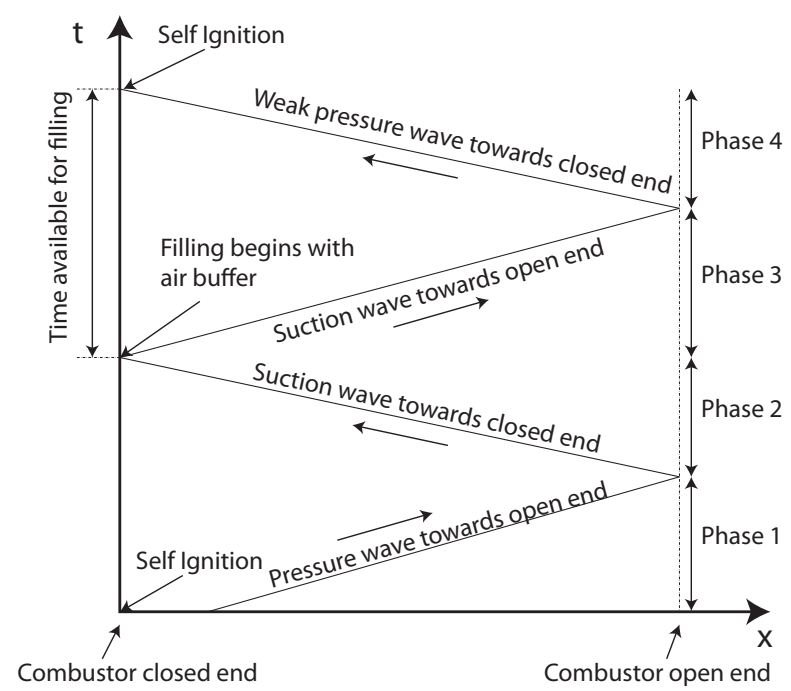

Figure 5: Time-space diagram of the shockless explosion combustion process and its four wave propagation phases

It ends when this suction wave arrives at the closed combustor end. Phase 3 starts just after its reflection at the closed combustor end. At this point the closed combustor end opens and the suction wave enables refilling of the tube. During refilling, exhaust gas is separated from the fresh mixture by an air buffer to prohibit local premature ignition. Phase 3 finishes when the suction wave reaches the open combustor end. Finally, during phase 4 the suction wave gets reflected again as a weak pressure wave at the open end and reaches the closed end of the combustor close to the time, where homogeneous ignition of the fresh mixture takes place. More details on the SEC process can be found in $29,11,13,28$.

For a resonant SEC operation the ignition delay time (IDT) and the combustor acoustic time scale must be of the same order of magnitude. Let $\theta$ be the time for phases 3 and 4 and the combustor tube length be $l_{\text {tube }}$. If $\alpha$ is the average speed of sound in the tube, then:

$$
\frac{2 \cdot l_{\text {tube }}}{\alpha}=\theta
$$


The time $\theta$ is a function of the combustor length and the average speed of sound in it. The latter depends on the composition of the gas in the combustor. A detailed computation of the acoustic time scale is only possible with timedepended 1-D computations [12. From past experience of the authors with simulations of the SEC process the average speed of sound is computed based on the assumption that $85 \%$ of the combustor volume is filled with burned gas and $15 \%$ unburned gas. The time $\theta$ must be equal to sum of the ignition delay time and the time during which only buffer air is injected in the combustor to avoid contact burning. In the current work, buffer gas injection will be neglected and $\theta$ must be equal to the ignition delay time of the mixture.

The ignition delay time is a function of the combustor conditions (pressure, temperature), the equivalence ratio and the fuel. In the present study dimethyl ether (DME) was chosen as a fuel due to its excellent ignitability and its potential as an alternative fuel [30, 31]. The ignition delay times of DME/air mixtures were calculated with a zero-dimensional simulations in Python. Cantera 32] was used for this purpose under the assumption of a homogeneous gas mixture in an adiabatic and isochoric batch reactor, as commonly used in kinetic studies e.g. in [33]. The overall ignition delay time was detected by the maximum temperature gradient in the temperature time history. To model the complex chemistry of the ignition of DME, a very recent and comprehensive chemical kinetic model AramcoMech 2.0 was employed [34, 35].

This leaves eq. 5 for the calculation of the length of the combustor tube:

$$
l_{\text {tube }}=\frac{\tau_{i g n} \cdot \alpha}{2}
$$

\subsection{Cycle topologies and simulation method}

Past detailed simulations of shockless explosion combustion have shown that the process is very sensitive to the inlet temperature, pressure and equivalence ratio of the combustible mixture [11, 12. At the same time, it is well know from simple ideal cycle studies [3] that the efficiency of the Humphrey cycle depends on the specific heat addition in the combustion process. This is a result of the 


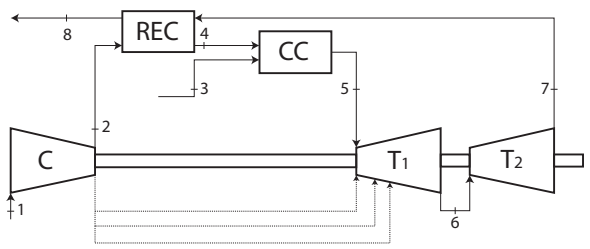

(a) Recuperated Joule

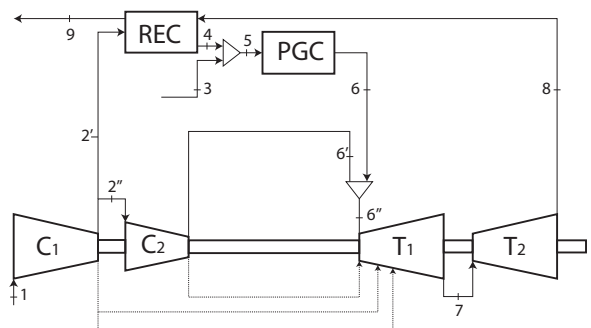

(c) Recuperated Humphrey - topology 2

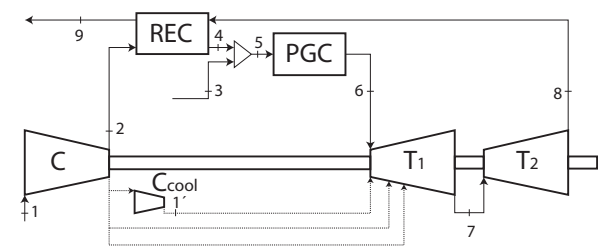

(b) Recuperated Humphrey - topology 1

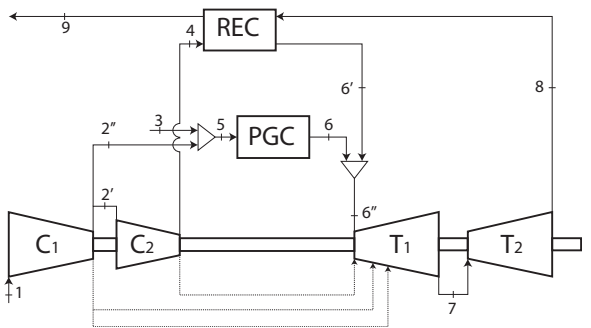

(d) Recuperated Humphrey - topology 3

Figure 6: Schematic representation of the studied cycle topologies with turbine cooling (category 2)

direct connection between combustor pressure gain and specific heat addition. Based on this consideration, the best option for the design of a recuperated cycle topology would be to operate the combustor close to stoichiometry. Dilution air can then be further compressed to cool the very hot exhaust at a temperature that a turbine can withstand. In such a case, there is a legitimate question about the way the recuperator is installed and which streams are actually fed into it to regain heat from the turbine exhaust. In order to account for the described design possibilities, three cycle topologies have been studied for the recuperated Humphrey cycle, along with the topologies presented for the Joule cycle in Fig. 6. Each topology has been studied for both categories (cooled or uncooled turbines), although Fig. 6 shows the cycle topologies for the category 2 cycles.

In topology 1 of the Humphrey cycle the compressor air flows through the recuperator and is preheated prior to its injection in the PGC combustor. A relatively small part of the compressor air is directed to an additional compressor 
that raises its pressure to the outlet pressure of the combustor. The compressor is split in two stages $\left(\mathrm{C}_{1}\right.$ and $\left.\mathrm{C}_{2}\right)$ in topologies 2 and 3 of the Humphrey cycle. The first stage delivers air to the combustor, while the second stage supplies the air for dilution in the combustor plenum and the cooling air of the first turbine stator row. In topology 2, the air that is fed to the combustor first flows through the recuperator to receive heat from the gas turbine exhaust. In topology 3 the air deliverer to the plenum is pre-heated in the recuperator. In both topologies the first turbine stator row cooling air is delivered directly without flowing through the recuperator.

Topology 1 is studied because it corresponds to the maximum possible degree of heat recuperation from the exhaust. This topology has the disadvantage that the combustor equivalence ratio is defined from the cycle operation and the energy balance around the combustor. Topologies 2 and 3, are studied because they allow the free choice of the combustor equivalence ratio. At the same time, these topologies realize different degrees of heat recuperation, which in turn also has an impact on the cycle and the combustor performance.

The reference configuration of all cycle topologies used the cycle parameters presented in Tab. 1. The category 1 cycles (uncooled turbine) have been modeled for cycle pressure ratios up to 10, while the category 2 cycles for values between 10 and 30 . In all cases, the pressure ratio of the first compressor stage $\left(\mathrm{C}_{1}\right.$ in Fig. 6] is defined as the cycle pressure ratio. Typically, the thermal efficiency of gas turbine cycles is compared at the same TIT. However, in the case of the recuperated cycle, material limitations define the upper limit of the exhaust gas inlet temperature in the recuperator. Hence, an upper boundary for the turbine outlet temperature is chosen based on existing recuperators. As a result, the current study compares the recuperated Humphrey cycle topologies to the recuperated Joule cycle at the same turbine outlet temperature (TOT), for the values presented in Tab. 1. This choice leads to a certain variation of the TIT for the studied cycle pressure ratios that will be analyzed in the results section. 


\section{Cycle performance results}

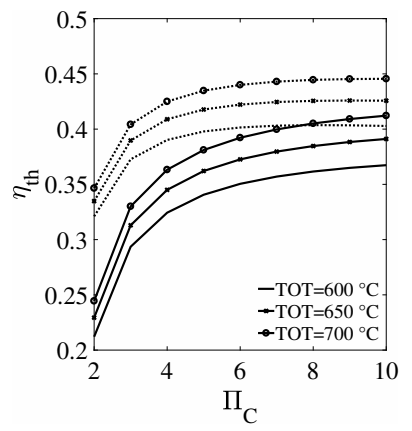

(a) Topology 1 , category 1

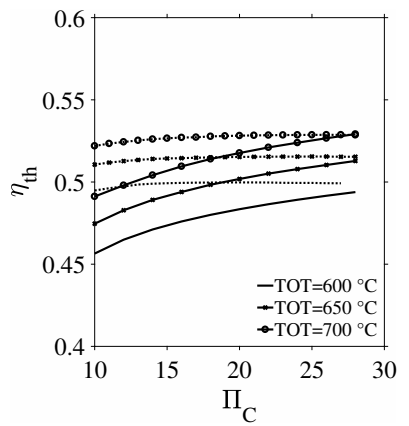

(d) Topology 1, category 2

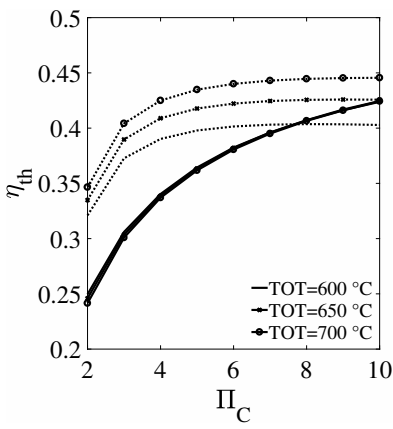

(b) Topology 2 , category 1

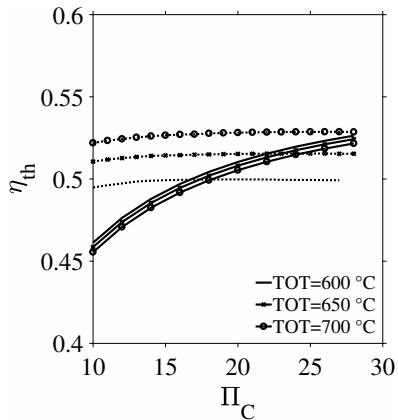

(e) Topology 2 , category 2

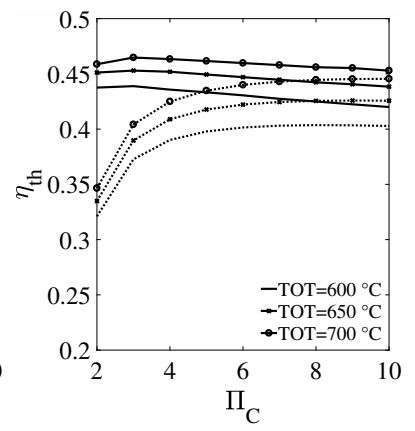

(c) Topology 3, category 1

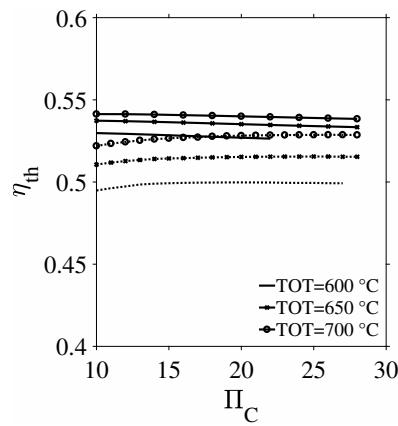

(f) Topology 3, category 2

Figure 7: Thermal efficiency of the three recuperated Humphrey cycle topologies (continuous) that of the Joule cycle (dashed)

Figure 7 compares the efficiency of all studied topologies and categories of the recuperated Humphrey cycle to that of the recuperated Joule cycle. This figure shows that cycle topology 1 does not deliver any efficiency increase, when applied in the uncooled or cooled Humphrey cycle categories (categories 1 and 2 respectively). Topology 2 does result in an efficiency increase for TOT values between 600 and $650^{\circ} \mathrm{C}$. More specifically, the highest efficiency increase for topology 2 is observed for the category 2 cycle at a TOT of $600^{\circ} \mathrm{C}$ and a $\Pi_{C}$ of 28 and it is equal to 3 percentage points. Topology 3 manages to deliver an efficiency increase in all studied cases, that is higher for low TOT and $\Pi_{C}$ values. By the same token, Fig. 8 presents the specific work generation of the 
studied cycles. Here, topology 1 has similar results for the Humphrey and the Joule cycle. On the contrary, both Huphrey cycle topologies 2 and 3 deliver a considerable increase in specific work generation. The reasons for this behavior are presented and analyzed in more depth in the following sections.
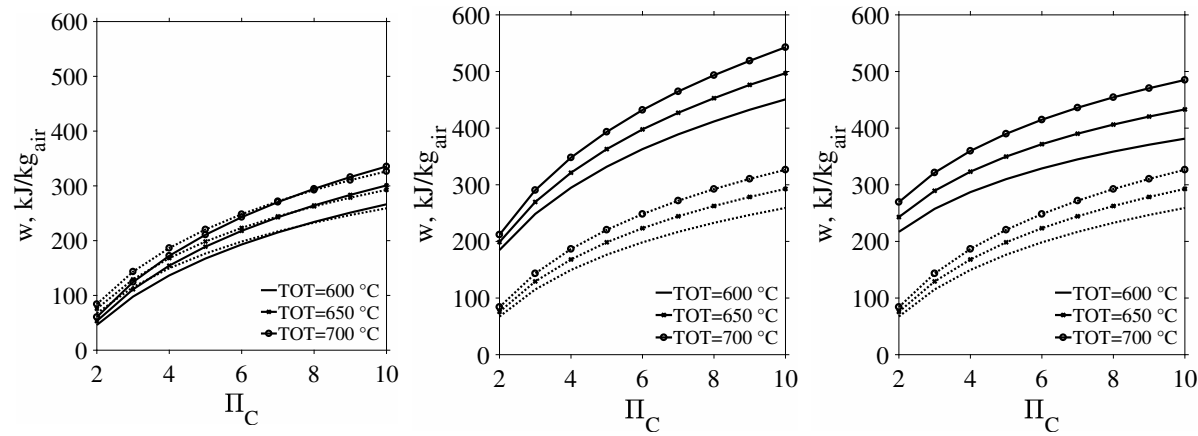

(a) Topology 1 , category 1

(b) Topology 2, category 1

(c) Topology 3, category 1
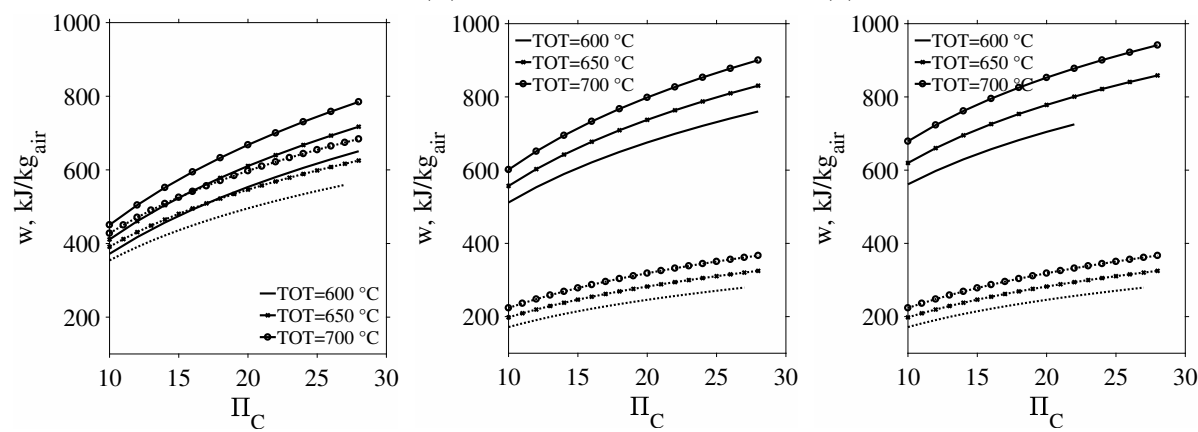

(d) Topology 1 , category 2

(e) Topology 2, category 2

(f) Topology 3, category 2

Figure 8: Specific work generation of the three recuperated Humphrey cycle topologies (continuous) that of the Joule cycle (dashed)

\subsection{Uncooled cycles - category 1}

The observed results come from a combination of different cycle parameters starting from the turbine inlet temperature. As can be seen from Fig. 9, the recuperated Humphrey cycle has generally a higher turbine inlet temperature than the Joule cycle.

Since all cycles are compared at the same turbine outlet temperature, the respective turbine inlet temperature is a direct function of the turbine expansion 


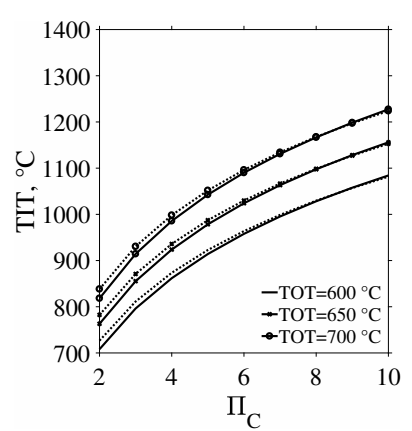

(a) Topology 1

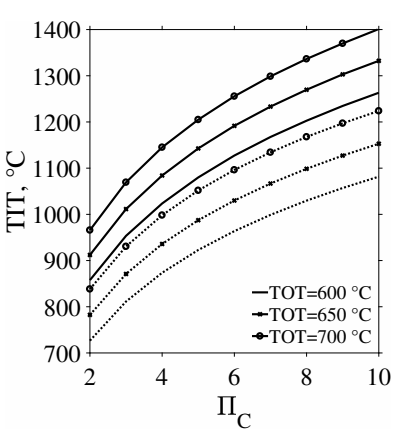

(b) Topology 2

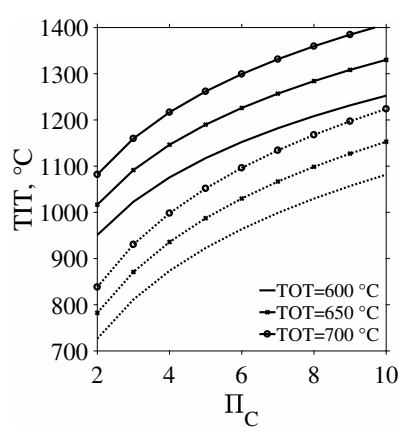

(c) Topology 3

Figure 9: Turbine inlet temperature for the uncooled Humphrey cycle topologies (continuous) and the Joule cycle (dashed).

ratio. The combustor pressure gain in the Humphrey cycle and the accompanying higher turbine expansion ratio are the cause for the observed higher TITs. As can be seen in Fig. 10, this is more pronounced for topologies 2 and 3, where the combustor of the Humphrey cycle burns stoichiometric mixtures and delivers a considerable pressure gain. In fact, the air stream fed in the combustor of topology 2 is first fed through the recuperator, which increases its temperature. This leads to a lower pressure gain in topology 2 than in topology 3 , where the respective air stream is not preheated. In contrary, the combustor in topology 1 is fed with the whole air stream preheated in the recuperator. This reduces

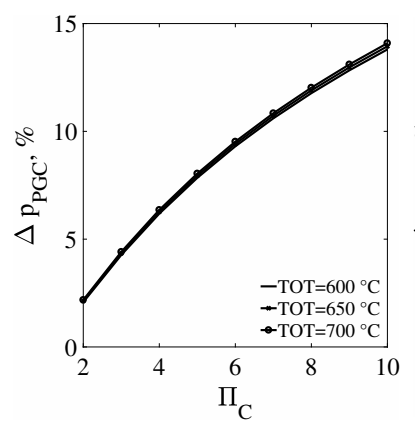

(a) Topology 1

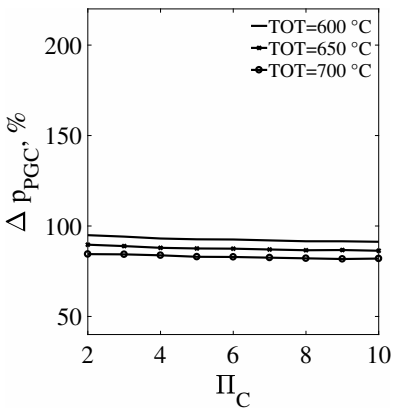

(b) Topology 2

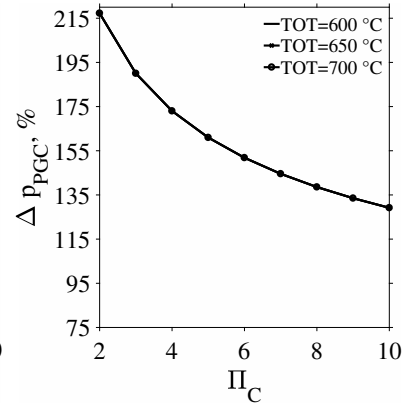

(c) Topology 3

Figure 10: Combustor pressure gain for the uncooled Humphrey cycle topologies (category 1) 
the equivalence ratio, the specific heat addition and the achieved pressure gain. Since it has been assumed that the Humphrey cycle combustor has a higher inlet pressure drop than the one of the Joule cycle, the resulting turbine expansion ratios are comparable and so are the TIT values.

In summary, the high combustor inlet temperature and its low equivalence ratio in topology 1 results in low pressure gain and no efficiency advantages of the recuperated Humhrey cycle. From Figures 7 and 9, one can also say that topologies 2 and 3 result efficiency gains but also in high TIT values. In fact, the latter are so high that cooling becomes necessary. Hence, the remaining of the analysis will focus on the category 2 cycles, where cooling is accounted for in the model.

\subsection{Cooled cycles - category 2}

This cycle category focuses on higher pressure ratios, where turbine cooling is necessary. As already mentioned, only topologies 2 and 3 of the recuperated Humphrey cycle deliver an efficiency advantage against the recuperated Joule cycle as can be seen from Figures $7 \mathrm{~d}$ - 7f. This happens even as the Humphrey cycle has higher TIT values in practically any cycle topology with turbine cooling (see Fig. 11). The higher TITs are a result of the pressure gain across the combustor, that is presented in Fig. 12. This however does not explain the counterintuitive results that despite higher TIT values the recuperated Humphrey cycle delivers a higher efficiency only for some cycle configurations in topologies 2 and 3 . To understand this, one has to understand the interconnection between recuperation, pressure gain and cooling air flow.

This is done first for topology 1 of the Humphrey cycle in Fig. 13 The recuperated Joule cycle achieves high efficiency by reusing the exhaust heat to reduce the amount of fuel that is consumed in the combustor. Since, the cycles have the same TOT and the flow rates in the recuperator are the same, the combustor inlet temperature takes the same value (see Fig. 13a). At the same time, the turbine inlet temperature - defined indirectly by the turbine outlet temperature - is fixed and thus lean mixtures (see 13b must be fed to 


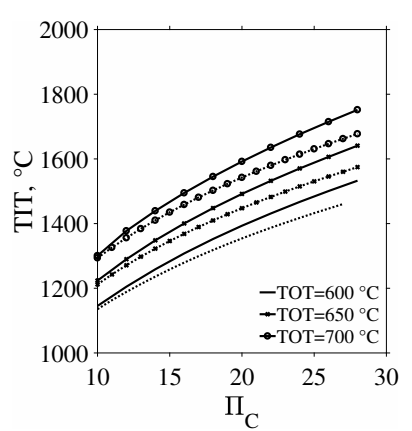

(a) Topology 1

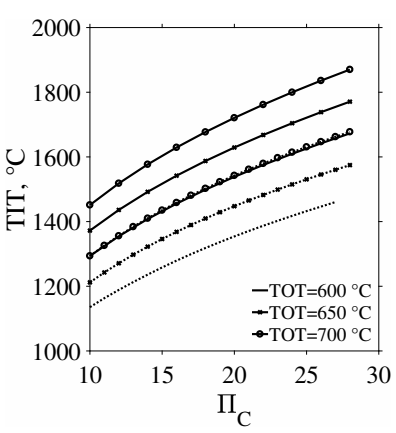

(b) Topology 2

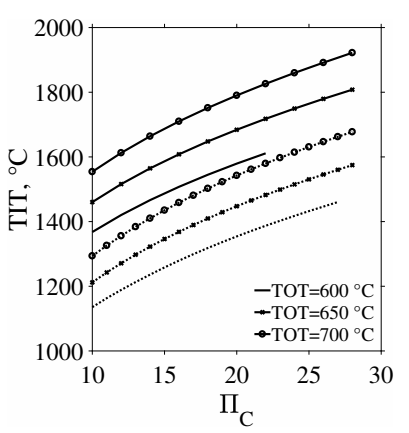

(c) Topology 3

Figure 11: Turbine inlet temperature for the cooled Humphrey cycle topologies (continuous) and the Joule cycle (dashed).

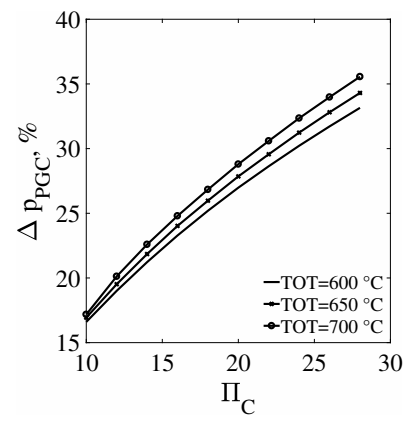

(a) Topology 1

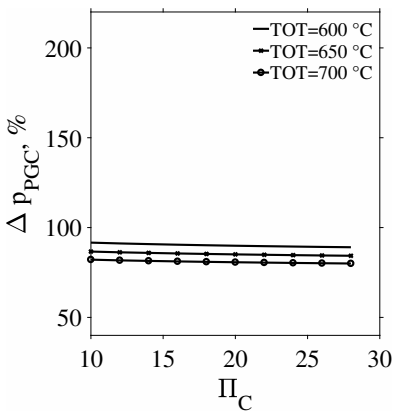

(b) Topology 2

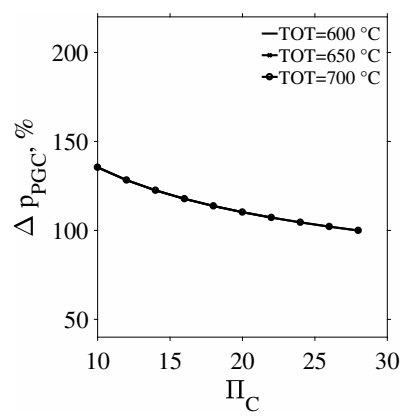

(c) Topology 3

Figure 12: Combustor pressure gain for the cooled Humphrey cycle topologies.

the combustors of both cycles due to their high inlet temperature. The high combustor inlet temperature and the low equivalence ratio lead to low combustor pressure gain in the Humphrey cycle (17\% and 35\%, depending on the pressure ratio). Even this rather limited pressure gain results in higher TIT values for the Humphrey cycle, in order to achieve the same TOT. In closer inspection of Figures $11 \mathrm{a}$ and $10 \mathrm{a}$ one can see that the difference in TIT values between the Humphrey cycle and the Joule cycle increases in the same way as the combustor pressure gain in the former. The same goes also for the combustor equivalence ratio shown in Fig. 13b. The reason for the comparable TIT values at low $\Pi_{C}$ values is the higher inlet pressure drop of the Humphrey cycle combustor. 
In these cases the combustor pressure gain simply counteracts its inlet pressure drop, thus leading to a similar TIT value. The net pressure gain in the remaining cases makes an additional compressor for the cooling air of the first turbine blade row necessary. This and the higher TIT values cause a relative increase in the cooling air mass flow rate in the Humphrey cycle with a negative impact on its efficiency.

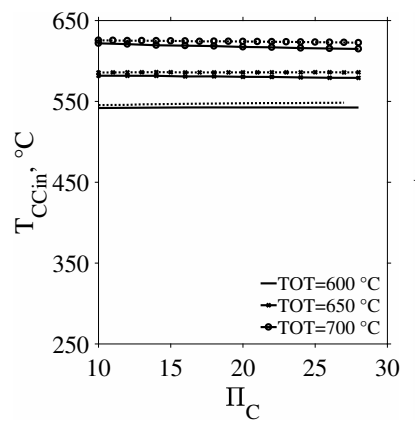

(a) Combustor inlet $\mathrm{T}$

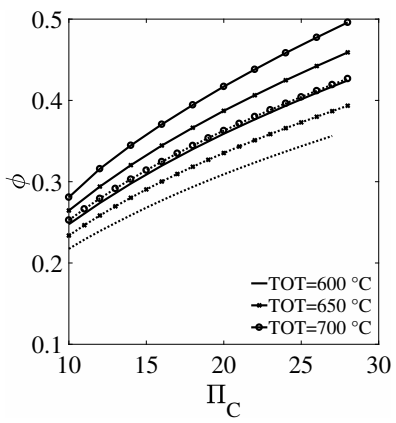

(b) Equivalence ratio

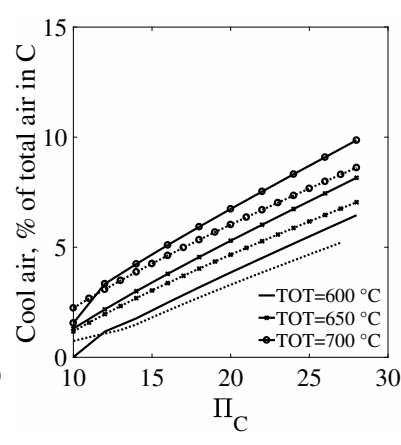

(c) Cooling air $\%$

Figure 13: Combustor inlet temperature, equivalence ratio and turbine cooling air as percentage of the compressor air flow for topology 1 of the cooled Humphrey cycle (continuous) and the Joule cycle (dashed).

In summary, good heat recuperation in topology 1 results in a high combustor inlet temperatures and low pressure gain. At the same time, the higher turbine inlet pressure in the Humphrey cycle results in higher TIT values for the same TOT and thus higher cooling air flow rates. In topology 1 the positive effects of combustor pressure gain on efficiency are counteracted from the combustor inlet pressure loss and the higher cooling air mass flow rate.

Based on this outcome and the fact that the Humphrey cycle delivers the highest efficiency advantage when its combustor operates close to stoichiometric conditions [3, topologies 2 and 3 were designed. In both topologies the combustor operates at an equivalence ratio of 1 . The air needed to reduce the turbine inlet temperature is bypassed in a plenum between combustor and turbine, where it mixes with the combustion products. This cycle design raises the question of which air stream should become the cold stream of the recuperator 
and what option leads to the highest cycle efficiency. In topology 2 the combustion air is fed to the recuperator, while in topology 3 the air directed to the plenum does. In topology 2 recuperation will have an effect on the combustor pressure gain through the resulting higher combustor inlet temperature. In contrast, in topology 3 recuperation has an effect only on the total amount of air fed to the combustor but not its pressure gain. The latter is only a function of the fuel type and the compressor outlet temperature (defined by the cycle pressure ratio).

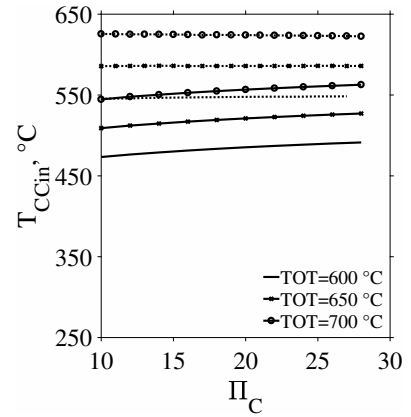

(a) Topology 2

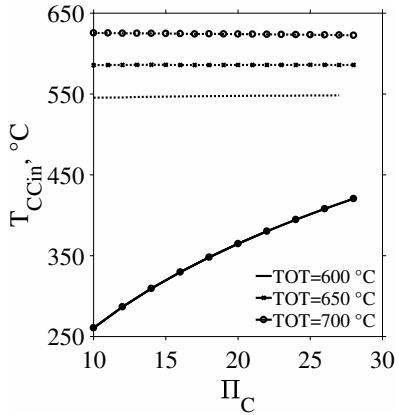

(b) Topology 3

Figure 14: Combustor inlet temperature for topologies 2 and 3 of the cooled Humphrey cycle (continuous) and the Joule cycle (dashed).

The effect of these design decisions on the combustor pressure gain and the combustor inlet temperature in the Humphrey cycle can be seen in Figures 12 and 14. respectively. In topology 2, in which the combustor air is first preheated in the recuperator and then fed to the combustor, the pressure gain lies between 75 and $95 \%$. Feeding the combustor air directly from the outlet of the compressor leads to the even higher pressure gain (between 100 and 140\%) in the combustor of topology 3 .

With these pressure gain values in the recuperated Huphrey cycle, one would expect much higher differences in efficiency, compared to the respective Joule cycle. Again, the reason for the rather limited efficiency gains lies in the effect of recuperation and cooling air flow. The pressure gain in the Humphrey cycle 
combustor again requires considerable compression of the cooling air for the first turbine row. This increases the cooling air temperature and thus its mass flow rate. At the same time, the high pressure gains also increase the turbine expansion ratio, thus resulting in higher TIT values for the same TOT. This causes a further increase of the turbine cooling air flow as can be seen in Fig. 15 . with the respective negative effects on cycle efficiency.

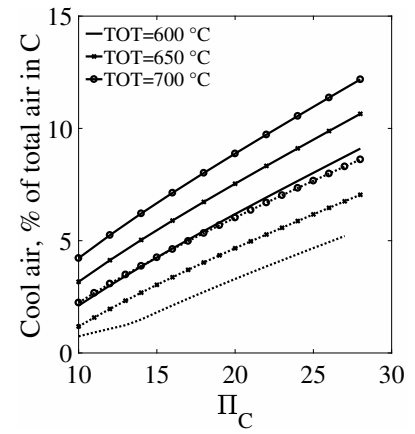

(a) Topology 2

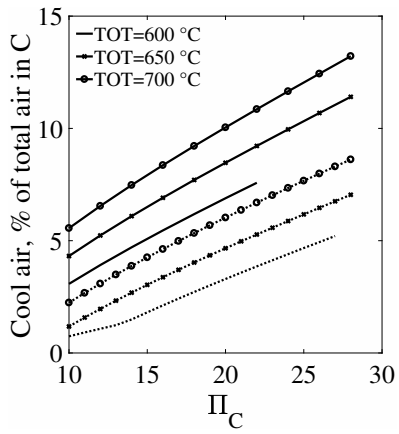

(b) Topology 3

Figure 15: Turbine cooling air as a percentage of compressor air for topologies 2 and 3 of the Humphrey cycle (continuous) and the Joule cycle (dashed).

Concerning th effect of recuperation, it has to be stressed that only part of the compressor air is fed through the recuperator in topologies 2 and 3 , as can be seen in Fig. 16. This might have a positive effect on the combustor pressure gain, but it comes with the downside of partial heat recuperation for the whole cycle. A good metric for that is the exhaust gas temperature. Since all cycles have exhaust gas mass flow rates that are comparable the temperature is an indication of the heat lost in environment. Figure 17 presents the cycle exhaust temperature for all studied cycle of category 2. As expected, the exhaust temperature of the Joule cycle is comparable to that of topology 1 of the Humphrey cycle. It becomes considerably higher for topologies 2 and 3 mainly due to the fact that lower air mass flow rates flow through the recuperator, which is assumed to retain the same effectiveness. More specifically, topology 3 has the highest exhaust temperatures, although it has generally higher air 


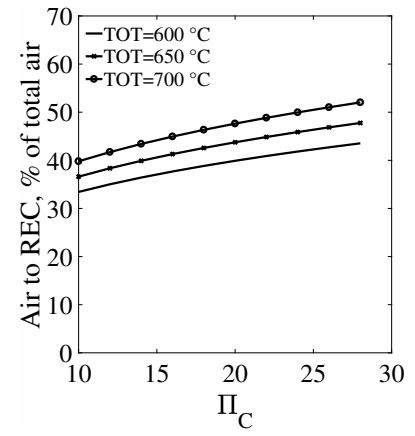

(a) Topology 2

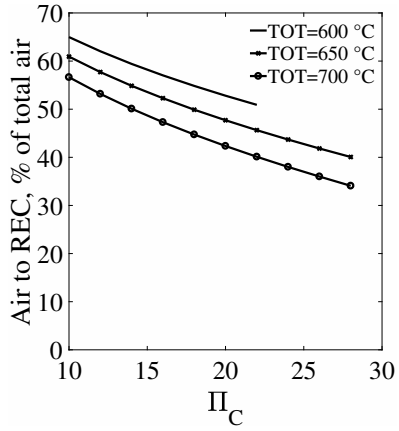

(b) Topology 3

Figure 16: Air fed to the recuperator as a percentage of compressor air for topologies 2 and 3 of the Humphrey cycle (continuous) and the Joule cycle (dashed).

mass flow rates going into the recuperator. The reason for this is the additional compression stage, necessary to reach the combustor exhaust pressure, that also increases the air inlet temperature in the recuperator.

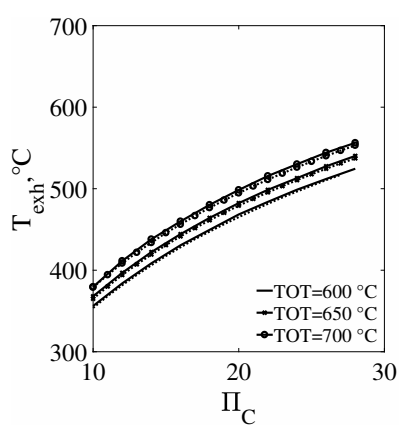

(a) Topology 1

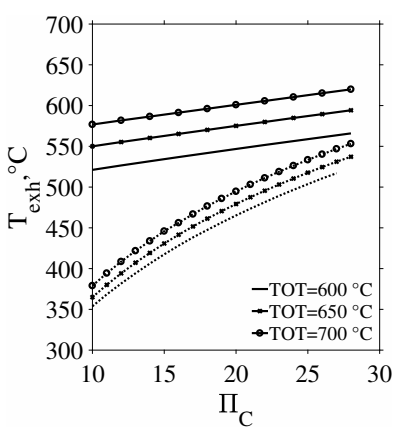

(b) Topology 2

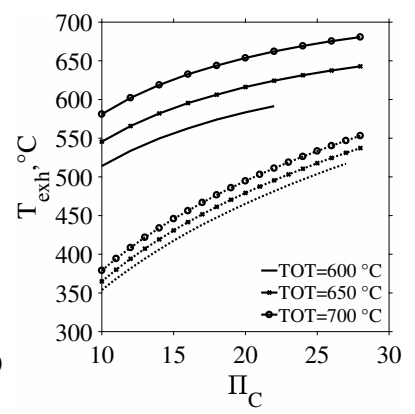

(c) Topology 3

Figure 17: Exhaust temperature for the cooled Humphrey cycles (continuous) and the Joule cycle (dashed).

In summary, topologies 2 and 3 manage to increase in some cases the efficiency of the recuperated Humphrey cycle, but the effect on efficiency is lower than that in the achieved combustor pressure gain, mainly to the reduced amount of recuperated heat and the increase in turbine cooling air flow. 


\section{Shockless explosion combustor design and operation}

In this section, the SEC combustor length is computed for the Humphrey cycle topologies and configurations that result in an efficiency advantage against the recuperated Joule cycle. This is done to evaluate how realistic it is, to consider SEC as a potential combustion technology for the studied cycles. The two other approximations of constant volume combustion (see section 1) are not expected to have any similar limitations in their design and thus would be viable for any one of the studied cycle topologies. The SEC combustor length is computed by calculating first the ignition delay times for the respective combustor operational conditions. The results are subsequently fed to eq. 5 to compute the combustor length.

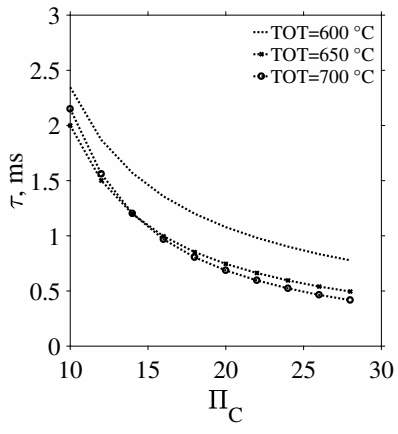

(a) Topology 2

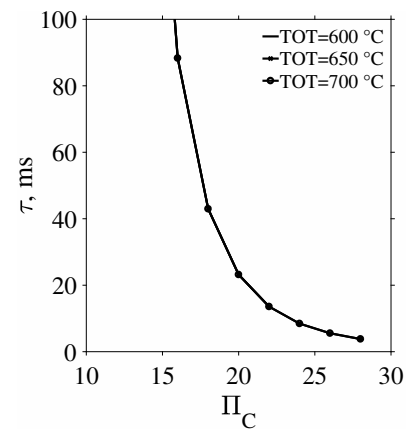

(b) Topology 3

Figure 18: Ignition delay time of the combustible mixtures for topologies 2 and 3 at the combustor inlet conditions of the respective cycles

Figure 18 shows the ignition delay time for the Humphrey cycle topologies 2 and 3. The ignition delay time is a function of the combustor inlet stream pressure, temperature and molar composition. In both presented topologies, the equivalence ratio is set equal to 1 and has no role in the observed differences. In both cases the ignition delay time is reduced for increasing cycle pressure ratio as a result of the corresponding higher pressure and temperature values at the combustor inlet (see Fig. 14). The comparison of the ignition delay time between the two topologies also reveals that the combustor inlet conditions for 


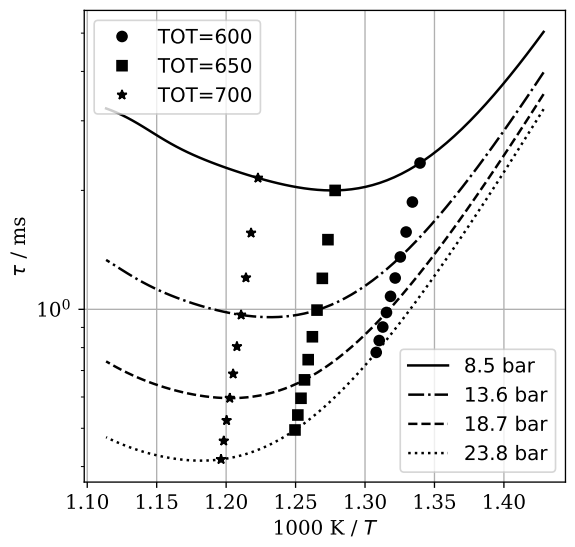

Figure 19: Ignition delay time of DME at four relevant pressures (lines) and cycle operational points for topology 2 and all studied TOT values

topology 2 result in ignition delay times one order of magnitude smaller than these of topology 3. Given the fact that the topologies are compared at the same $\phi$ and $\Pi_{C}$, the different combustor inlet temperatures between the topologies are responsible for this effect. Focusing on topology 2 one can observe that the cycles with TOT values $650^{\circ} \mathrm{C}$ and $700{ }^{\circ} \mathrm{C}$ result in comparable ignition delay times. Again, the pressure and equivalence ratio of the compared cycle configurations are the same, so the only variable responsible for this behavior is the combustor inlet temperature. In order to understand this behavior, the dependence of the ignition time delay of DME with temperature at the pressures in question has to be studied in more detail. More specifically, Fig. 19 shows the ignition delay time values of DME as a function of temperature at four representative pressures that correspond to the $\Pi_{C}$ values 10, 15, 20 and 25 respectively. At the same time, all the combustor operational points (inlet temperature and pressure) and the respective ignition delay times are depicted in Fig. 19 for the TOT values of $600{ }^{\circ} \mathrm{C}, 650{ }^{\circ} \mathrm{C}$ and $700{ }^{\circ} \mathrm{C}$.

Finally, Fig. 20 presents the SEC combustor length corresponding to the ignition delay times shown in Fig. 18 . As expected, the conditions at the combustor inlet of topology 3 result in much higher combustor lengths than in topology 


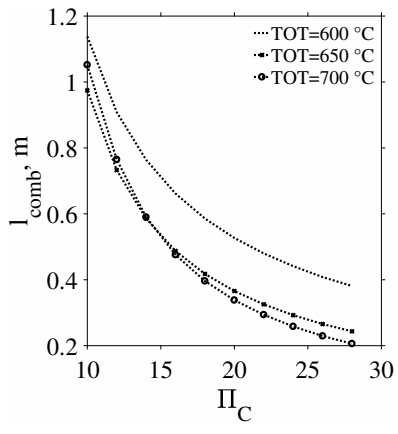

(a) Topology 2

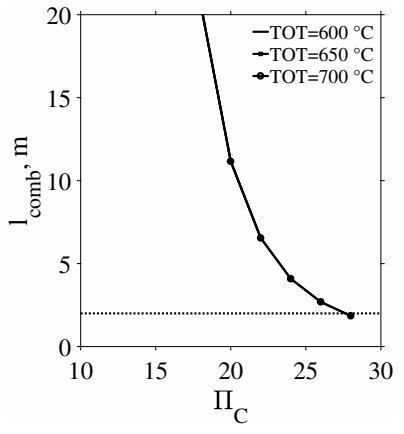

(b) Topology 3

Figure 20: SEC combustor length for topologies 2 and 3 and at the combustor inlet conditions of the respective cycles

2. In what concerns the feasibility of construction for such a combustor, gas turbine combustors are typically compact and do not exceed a length of 1 meter. If one considers a more conservative maximum combustor length of 2 meters, all cycle configurations of topology 2 will result in realistic combustor lengths and could be feasible. In this case one has to refer to Fig. 7 to choose the cycle configuration of topology 2 with the highest efficiency advantage. Specifically, this would result in cycles with TOT values between $600{ }^{\circ} \mathrm{C}$ and $650{ }^{\circ} \mathrm{C}$ and $\Pi_{C}$ values above 18 and 23, respectively. In contrast, only the cycle configurations with pressure ratios above 28 will result in realistic combustor lengths for topology 3. At this high pressure ratio only cycles with TOT values above $650{ }^{\circ} \mathrm{C}$ are feasible and will result in efficiency advantages against the recuperated Joule cycle. This is in contrast to the results of the steam injected Humphrey cycle topologies presented in the work of Stathopoulos et al. [20], where hardly any cycle configuration would result in a realistic combustor lengths.

\section{Summary of conclusions}

The current work has presented a thorough analysis of the recuperated Humphrey cycle for gas turbines with pressure gain combustion. Three different cycle topologies were studied, with and without turbine cooling. In the case of 
the cycles without turbine cooling, mostly topology 3 resulted in efficiency advantages. However, in these cases the resulting turbine inlet temperature values were so high, that turbine cooling would have been necessary. As a result, only recuperated cycles with turbine cooling have been further studied in the current work.

From the cycle topologies with turbine cooling, topologies 2 and 3 demonstrated efficiency advantages against the Joule cycle. The cycle efficiency and combustor pressure gain in the recuperated Humphrey cycle have been found to be connected with recuperation in a complex way. In topology 1, where the air leaving the compressor is entirely fed to the recuperator, the recuperated Humphrey cycle cannot deliver any efficiency advantages against the recuperated Joule cycle. The high combustor inlet temperature results to low equivalence ratios and thus limited combustor pressure gain. The latter merely counteracts the inlet pressure loss of the combustor and does not effect any efficiency increase. By using topologies 2 and 3, the effect of As a result, higher combustor pressure ratios and thus higher cycle efficiencies were achieved. However, the degree of heat recuperation was also stepwise reduced. This limited the efficiency gains against the recuperated Joule cycle.

This work is additionally an attempt to benchmark the cycle topologies and configurations for which shockless explosion combustion could be applied with realistic combustor lengths. This was done only for the cycle topologies and configurations that achieved an efficiency advantage against the Joule cycle. It was found that all studied configurations for topology 2 resulted in feasible SEC combustors. For topology 3 the cycle configuration with pressure ratios above 28 have feasible combustor lengths.

\section{Acknowledgment}

The authors gratefully acknowledge the support by the Deutsche Forschungsgemeinschaft(DFG) as part of the Collaborative Research Center SFB 1029 Substantial efficiency increase in gas turbines through direct use of coupled unsteady 
combustion and flow dynamics in projects A08 and D01.

\section{Symbols}

Latin characters

C Turbine cooling technology level constant

$c_{v} \quad$ Specific heat capacity under constant volume $\frac{\mathrm{kJ}}{\mathrm{kgK}}$

$c_{p} \quad$ Specific heat capacity under constant pressure $\quad \frac{k J}{k g K}$

$d p_{C C} \quad$ Combustor inlet pressure drop $\quad \%$ of $p_{\text {in }}$

$\mathrm{K} \quad$ Cooling air injection pressure loss constant

$l_{\text {comb }} \quad$ SEC combustor length $\mathrm{m}$

$\dot{m} \quad$ Mixture mass flow rate $\frac{\mathrm{kg}}{\mathrm{s}}$

$\dot{m}_{\text {air }} \quad$ Compressor inlet mass flow rate $\frac{\mathrm{kg}}{\mathrm{s}}$

$p_{A} \quad$ Combustor inlet pressure bar

$p_{B} \quad$ Combustor pressure at the end of the bar

constant volume heat addition process

$p_{3} \quad$ Combustor outlet pressure bar

$Q \quad$ Heat added through combustion W

$\Delta p_{P G C} \quad$ Humphrey cycle combustor pressure gain $\quad \%$ of $p_{\text {in }}$

$\delta p_{r c} \quad$ Pressure drop in cold side of recuperator

$\delta p_{r h} \quad$ Pressure drop in hot side of recuperator

$\delta p_{\text {stage }} \quad$ Expansion ratio of each turbine stage

$\delta p_{\text {mix }} \quad$ Relative pressure drop due to cooling air $\quad \%$ of $p_{\text {in }}$

mixing in the main exhaust stream

$\delta p_{\text {mixer }} \quad$ Relative pressure drop in the mixing $\quad \%$ of $p_{\text {in }}$

element at the combustor inlet

$S t_{g} \quad$ External Stanton number

$T_{A} \quad$ Combustor inlet temperature $\quad{ }^{\circ} \mathrm{C}$

$T_{B} \quad$ Combustor temperature at the end of the $\quad{ }^{\circ} \mathrm{C}$

constant volume heat addition process

$T_{b l} \quad$ Blade temperature used for cooling air calculations $\quad{ }^{\circ} \mathrm{C}$ 


$\begin{array}{llc}T_{C C i n} & \text { Combustor inlet temperature } & { }^{\circ} \mathrm{C} \\ T_{\text {exh }} & \text { Cycle exhaust temperature } & { }^{\circ} \mathrm{C} \\ \text { TIT } & \text { Turbine inlet temperature } & { }^{\circ} \mathrm{C} \\ \text { TOT } & \text { Turbine outlet temperature } & { }^{\circ} \mathrm{C} \\ w & \text { Cycle specific work } & \frac{k J}{k g_{a i r}}\end{array}$

\section{Greek letters}

\begin{tabular}{|c|c|c|}
\hline$\alpha$ & Speed of sound & \\
\hline$\gamma$ & Specific heat capacity ratio & \\
\hline$\epsilon$ & Recuperator effectiveness & \\
\hline$\epsilon_{f}$ & Turbine stage film cooling effectiveness & \\
\hline$\eta_{i s C}$ & Compressor isentropic efficiency & \\
\hline$\eta_{i s C-c o o l}$ & Cooling air compressor isentropic efficiency & \\
\hline$\eta_{\text {Cooling }}$ & Cooling air efficiency & \\
\hline$\eta_{i s T}$ & Turbine stage isentropic efficiency & \\
\hline$\eta_{t h}$ & Cycle thermal efficiency & \\
\hline$\theta$ & Half period of the SEC process & seconds \\
\hline$\nu$ & Specific volume & $\frac{m^{3}}{k g}$ \\
\hline$\Pi_{C}$ & Compressor pressure ratio & \\
\hline$\rho$ & Density & $\frac{\mathrm{kg}}{\mathrm{m}^{3}}$ \\
\hline$\tau$ & Ignition delay time & seconds \\
\hline
\end{tabular}

$\phi \quad$ Combustion process global equivalence ratio

$\begin{array}{ll}\text { Abbreviations } & \\ C P C & \text { Constant pressure combustion } \\ C V C & \text { Constant volume combustion } \\ D M E & \text { Dimethyl Ether } \\ I D T & \text { Ignition delay time }\end{array}$




$\begin{array}{ll}P G C & \text { Pressure gain combustion } \\ P D C & \text { Pulsed detonation combustion } \\ R D C & \text { Rotating detonation combustion } \\ S E C & \text { Shockless explosion combustion } \\ Z N D & \text { Zeldovich, von Neumann, Dörring }\end{array}$

\section{References}

[1] ENTSO-E, Scenario outlook and adequacy forecast, Tech. Rep. June, ENTSO-E (2015).

[2] B. Buchholz, Z. Styczynski, Smart Grids - Fundamentals and Technologies in Electricity Networks, Springer Vieweg, 2014.

[3] W. Heiser, D. Pratt, Thermodynamic cycle analysis of pulse detonation engines, Journal of Propulsion and Power 18 (1) (2002) 86-76.

[4] C. A. Nordeen, Thermodynamics of a Rotating Detonation Engine, Phd thesis, University of Connecticut (2013).

[5] P. Stathopoulos, J. Vinkeloe, C. O. Paschereit, Thermodynamic evaluation of constant volume combustion for gas turbine power cycles, Proceedings of the 11th International Gas Turbine Congress, Tokyo, Japan, 2015.

[6] T. Bratkovich, T. Bussing, A pulse detonation engine performance model, in: Proceedings of the 31st Joint Propulsion Conference and Exhibit, American Institute of Aeronautics and Astronautics (AIAA), 1995.

[7] E. Bach, M. Bohon, C. O. Paschereit, P. Stathopoulos, Development of an Instrumented Guide Vane Set for RDC Exhaust Flow Characterization, in: Proceedings of the 2018 Joint Propulsion Conference, American Institute of Aeronautics and Astronautics, Reston, Virginia, 2018.

[8] P. Wolański, Detonative propulsion, Proceedings of the Combustion Institute 34 (1) (2013) 125-158. 
[9] D. A. Schwer, R. F. Johnson, A. Kercher, D. Kessler, A. T. Corrigan, Progress in Efficient, High-Fidelity, Rotating Detonation Engine Simulations, in: Proceedings of the AIAA Scitech 2019 Forum, American Institute of Aeronautics and Astronautics, Reston, Virginia, 2019.

[10] D. Paxson, K. Dougherry, Operability of an Ejector Enhanced Pulse Combustor in a Gas Turbine Environment, in: Proceedings of the 46th AIAA Aerospace Sciences Meeting and Exhibit, American Institute of Aeronautics and Astronautics, Reston, Virigina, 2008.

[11] T. Rähse, C. Paschereit, P. Stathopoulos, P. Berndt, R. Klein, Gas dynamic simulation of shockless explosion combustion for gas turbine power cycles, in: Proceedings of the ASME Turbo Expo, Vol. 3, 2017.

[12] T. S. Rähse, P. Stathopoulos, J.-S. Schäpel, F. Arnold, R. King, On the influence of fuel stratification and its control on the efficiency of the shockless explosion combustion cycle, in: Proceedings of ASME Turbo Expo, ASME International, Oslo, Norway, 2018.

[13] T. G. Reichel, J.-S. Schäpel, B. C. Bobusch, R. Klein, R. King, C. Oliver Paschereit, Shockless Explosion Combustion: Experimental Investigation of a New Approximate Constant Volume Combustion Process, Journal of Engineering for Gas Turbines and Power 139 (2) (2016) 021504.

[14] P. Berndt, R. Klein, Modeling the kinetics of the Shockless Explosion Combustion, Combustion and Flame 175 (2017) 16-26.

[15] B. Boust, Q. Michalski, M. Bellenoue, Experimental Investigation of Ignition and Combustion Processes in a Constant-Volume Combustion Chamber for Air-Breathing Propulsion, in: Proceedings of the 52nd AIAA/SAE/ASEE Joint Propulsion Conference, American Institute of Aeronautics and Astronautics, Reston, Virginia, 2016.

[16] D. Paxson, T. Kaemming, Foundational performance analyses of pressure gain combustion thermodynamic benefits for gas turbines, in: Proceedings 
of the 50th AIAA Aerospace Sciences Meeting including the New Horizons Forum and Aerospace Exposition, American Institute of Aeronautics and Astronautics (AIAA), 2012.

[17] T. Endo, T. Fujiwara, A Simplified Analysis on a Pulse Detonation Engine Model., Transactions of the Japan Society for Aeronautical and space sciences 44 (146) (2002) $217-222$.

[18] M. R. Nalim, Thermodynamic limits of work and pressure gain in combustion and evaporation processes, Journal of propulsion and power 18 (6) (2002) 1176-1182.

[19] D. A. Schwer, C. M. Brophy, R. H. Kelso, Pressure Characteristics of an Aerospike Nozzle in a Rotating Detonation Engine, in: Proceedings of the 2018 Joint Propulsion Conference, American Institute of Aeronautics and Astronautics, Reston, Virginia, 2018.

[20] P. Stathopoulos, T. Rähse, J. Vinkeloe, N. Djordjevic, Steam injected humphrey cycle for gas turbines with pressure gain combustion, Energy 188.

[21] N. Neumann, D. Peitsch, Potentials for pressure gain combustion in advanced gas turbine cycles, Applied Sciences 9 (16).

[22] P. Stathopoulos, Comprehensive Thermodynamic Analysis of the Humphrey Cycle for Gas Turbines with Pressure Gain Combustion, Energies 11 (12).

[23] P. Stathopoulos, C. Paschereit, Retrofitting micro gas turbines for wet operation. A way to increase operational flexibility in distributed CHP plants, Applied Energy 154 (2015) 438 - 446.

[24] P. Stathopoulos, C. O. Paschereit, Operational Strategies of Wet-Cycle Micro Gas Turbines and Their Economic Evaluation, Journal of Engineering for Gas Turbines and Power 138 (12). 
[25] P. Stathopoulos, J. Fernàndez-Villa, On the Potential of Power Generation from Thermoelectric Generators in Gas Turbine Combustors, Energies $11(10)$.

[26] J. Kurzke, Performance Modeling Methodology: Efficiency Definitions for Cooled Single and Multistage Turbines, in: Proceedings of the ASME Turbo Expo 2002: Power for Land, Sea, and Air, no. 36061, 2002, pp. $85-92$.

[27] J. H. Horlock, Advanced Gas Turbine Cycles, Referex Engineering, Pergamon, 2003.

[28] F. Yücel, F. Völzke, C. Paschereit, Effect of the Switching Times on the Operating Behavior of a Shockless Explosion Combustor, in: R. King (Ed.), Active Flow and Combustion Control, Notes on Numerical Fluid Mechanics and Multidisciplinary Design, Springer, 2018, pp. 121-134.

[29] B. C. Bobusch, P. Berndt, C. O. Paschereit, R. Klein, Shockless explosion combustion: An innovative way of efficient constant volume combustion in gas turbines, Combustion Science and Technology 186 (10-11) (2014) $1680-1689$.

[30] M. Matzen, Y. Demirel, Methanol and dimethyl ether from renewable hydrogen and carbon dioxide: Alternative fuels production and life-cycle assessment, Journal of Cleaner Production 139 (2016) 1068-1077.

[31] M. Gentzen, D. Doronkin, T. Sheppard, J.-D. Grunwaldt, J. Sauer, S. Behrens, An intermetallic Pd2Ga nanoparticle catalyst for the singlestep conversion of CO-rich synthesis gas to dimethyl ether, Applied Catalysis A: General 562 (2018) 206-214.

[32] D. G. Goodwin, R. L. Speth, H. K. Moffat, B. W. Weber, Cantera: An object-oriented software toolkit for chemical kinetics, thermodynamics, and transport processes, https://www. cantera.org (2018). 
[33] U. Burke, K. P. Somers, P. O'Toole, C. M. Zinner, N. Marquet, G. Bourque, E. L. Petersen, W. K. Metcalfe, Z. Serinyel, H. J. Curran, An ignition delay and kinetic modeling study of methane, dimethyl ether, and their mixtures at high pressures, Combustion and Flame 162 (2) (2015) 315-330.

[34] A. Kéromnès, W. K. Metcalfe, K. A. Heufer, N. Donohoe, A. K. Das, C.J. Sung, J. Herzler, C. Naumann, P. Griebel, O. Mathieu, M. C. Krejci, E. L. Petersen, W. J. Pitz, H. J. Curran, An experimental and detailed chemical kinetic modeling study of hydrogen and syngas mixture oxidation at elevated pressures, Combustion and Flame 160 (6) (2013) 995-1011.

[35] Y. Li, C.-W. Zhou, K. P. Somers, K. Zhang, H. J. Curran, The oxidation of 2-butene: A high pressure ignition delay, kinetic modeling study and reactivity comparison with isobutene and 1-butene, Proceedings of the Combustion Institute 36 (1) (2017) 403-411. 